\title{
Chemical composition of the Kojaku granite pluton, southwestern Japan
}

\author{
T. FUKUHARA ${ }^{1 *}$ AND M. TSUBOI ${ }^{1}$
}

${ }^{1}$ Sci. Tech., Kwansei Gakuin Univ., 2-1 Gakuen, Sanda, Hyogo 669-1337, Japan (*correspondence:

enf05948@kwansei.ac.jp)

The Kojaku granite locates at the northern part of Lake Biwa, southwestern Japan. There are seven granitic plutons around Lake Biwa area. The granitic plutons in this area are divided into 2 stages from their ages; the older plutons (100 - $90 \mathrm{Ma})$ and younger plutons ( $80-66 \mathrm{Ma}$ ). The Kojaku granite belongs to the younger group [1]. The Kojaku granite consists of two bodies, the Tsuruga body and the Kojaku body. Both of bodies consist of coarse-grained, medium-grained and finegrained biotite granite [2]. The granite intrudes into sedimentary rocks of Jurassic accretionary complex of MinoTamba belt. This study focuses on chemical composition of the Kojaku body of the Kojaku granite to understand the petrogenesis of the pluton. The age of this pluton is $57.4 \pm 5.1$ $\mathrm{Ma}(\mathrm{Rb}-\mathrm{Sr}$ whole rock isochron age) [3] and 68.0 - 69.2 Ma (zircon U-Pb age) [4]. Major and trace elements were measured by wavelength dispersive type $\mathrm{X}$-ray fluorescence method. REE compositions were measured by inductively coupled plasma mass spectrometry. $\mathrm{SiO}_{2}$ content ranges from 72.3 to $79.3 \mathrm{wt} . \%$. Aluminum saturation index ranges from 0.96 to 1.27 and shows both characteristics of I and S type. Magnetic susceptibility mainly shows ilmenite series, a few are magnetite series. REE pattern shows negative Eu anomaly and HREE flat. The Kojaku granite has multiple chemical characteristics within a pluton.

[1] Sugii et al. (1999) Geoscience Rept. Shimane Univ. 18, 69-84. [2] Sawada et al. (1997) Earth Science 51, 401-412. [3] Tainosho et al. (1999) Memoirs of Geological Society of Japan 53, 309-321. [4] Sueoka et al. (2018) Journal of Geography 127, 795-803. 